\title{
Correction: Diagnostic Criteria for Depression in Type 2 Diabetes: A Data-Driven Approach
}

The PLOS ONE Staff

In Fig. 1, the line and data points for Cluster 1 are missing. Please see a complete, correct version of Fig. 1 below.

\section{G open access}

Citation: The PLOS ONE Staff (2015) Correction: Diagnostic Criteria for Depression in Type 2 Diabetes: A Data-Driven Approach. PLoS ONE 10(3): e0122324. doi:10.1371/journal.pone.0122324

Published: March 23, 2015

Copyright: $\odot 2015$ The PLOS ONE Staff. This is an open access article distributed under the terms of the Creative Commons Attribution License, which permits unrestricted use, distribution, and reproduction in any medium, provided the original author and source are credited. 


\section{Symptom profiles of latent classes}

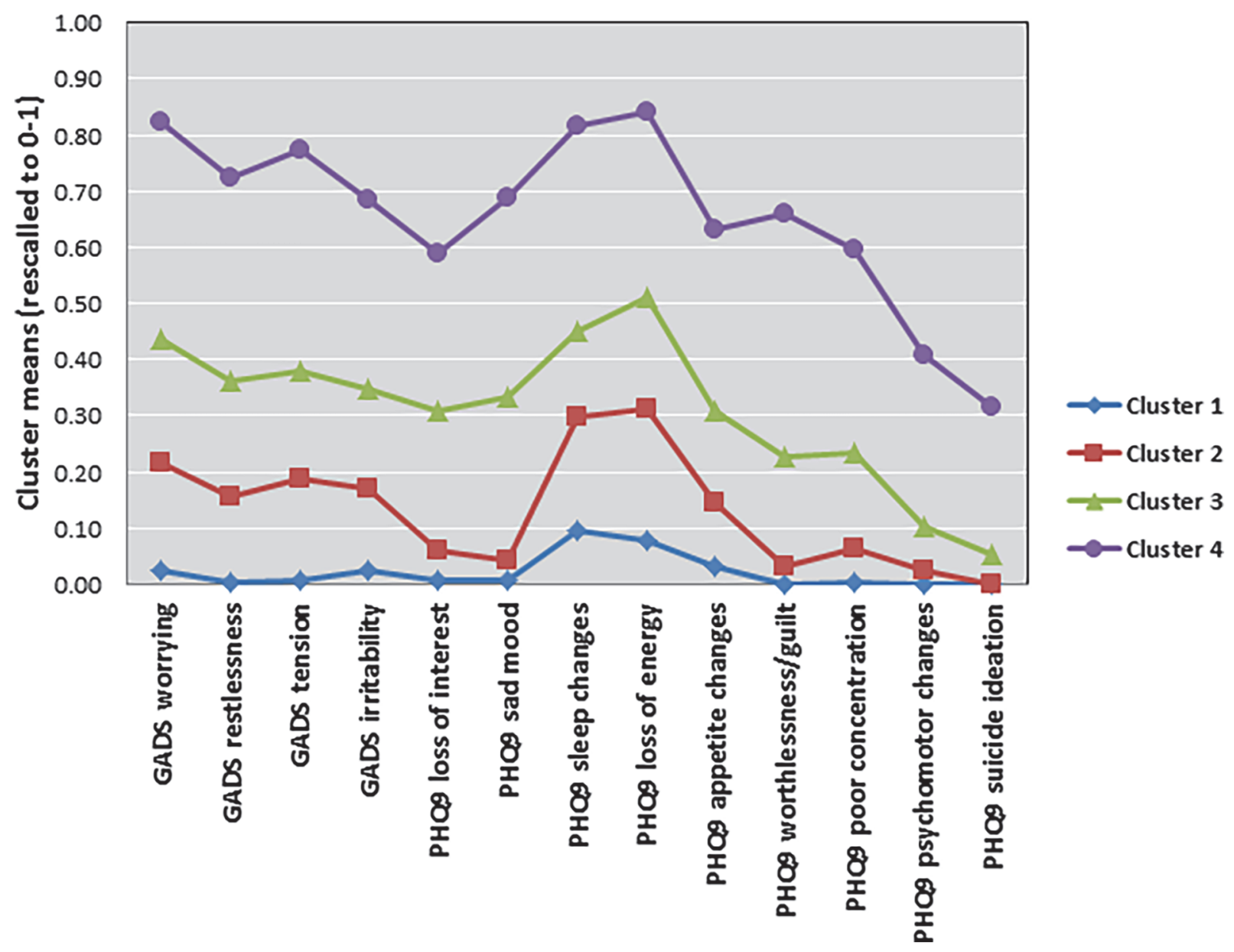

Fig 1. Symptom profile of the 4 (ordered) latent class model graph showing partial conditional probabilities for the 4-class model (LCA response profiles).

doi:10.1371/journal.pone.0122324.g001

\section{Reference}

1. Starkstein SE, Davis WA, Dragovic M, Cetrullo V, Davis TME, Bruce DG (2014) Diagnostic Criteria for Depression in Type 2 Diabetes: A Data-Driven Approach. PLoS ONE 9(11): e112049. doi:10.1371/ journal.pone.0112049 PMID: 25390370 